\title{
The Implication of Conjunctive Element Shifts in the Translation of Argumentative Texts
}

\author{
SIEW HUI SHENG \\ SOH BEE KWEE \\ *LOOI WAI LING \\ Malaysian Languages and Applied Linguistics, Faculty of Languages and Liguistics, \\ University of Malaya, 50603 Kuala Lumpur, Malaysia \\ *Corresponding author: looiwl@um.edu.my
}

Published online: 20 April 2018

To cite this article: Siew, H.S., Soh, B.K. and Looi, W.L. 2018. The implication of conjunctive element shifts in the translation of argumentative texts. KEMANUSIAAN the Asian Journal of Humanities 25(1): 19-41, https://doi.org/10.21315/kajh2018.25.1.2

To link to this article: https://doi.org/10.21315/kajh2018.25.1.2

\begin{abstract}
This study attempts to identify the implication of conjunctive element shifts in the Chinese translation of argumentative column articles by an established columnist. More specifically, this study focuses on the implication of a cohesive shift, which includes explicitations, implicitations, shifts and wrong translations of conjunctive elements in the translated text. The texts in this study are argumentative in nature, and the use of conjunctive elements is pivotal in guiding the reader on the flow of the argument at hand. Through indepth analysis and observation, it is found that changes in conjunctive elements can affect a translation in six possible ways: altering the intensity of the message, shifting the focus of the message, altering the tone and manner of the texts, causing repetitious and intrusive translations, changing the interpretation of the text, and altering the conversational-like element in the source text.
\end{abstract}

Keywords and phrases: conjunctive elements, translation, argumentative texts, shifts, explicitation

\section{Introduction}

Most studies on conjunctive elements (CEs) in translation have focused on the explicitation of these elements in the translated texts (TTs). Much work has been done to prove the explicitation hypothesis, which states that TTs are prone to additions of CEs. To date, the implications of explicitation have not been widely studied, nor have the implications of other phenomena, such as implicitation, shifts or wrong translations. CEs play an important role in argumentative texts, 
because they have the ability to establish logical relations and to instruct the readers on the way a text should be comprehended (Baker 2001, 190; BulowMoller 1989, 142; Morenberg 2002, 134). Therefore, it would be beneficial to investigate the implicitation of $\mathrm{CE}$ shifts in the translation of argumentative texts since argumentative texts rely heavily on thesis and supporting evidence with logic as their backbone (Hatim and Mason 1990). The argumentative texts selected are articles from Karim Raslan, a commentator on current issues, especially those concerning Malaysia, in South-East Asia.

\section{Review of Literature}

This section will begin by discussing the concept of CEs, followed by the notion of cohesive shifts and will review the literature regarding the implications of $\mathrm{CE}$ shifts in TTs.

\section{Conjunctive elements}

Conjunctions has been studied under different labels, each one having its own justification for including or excluding certain CEs. Some of these labels are: links, connectors (Werth 1984; Bulow-Moller 1989), conjunctions (Halliday and Hasan 2001; Baker 2001; Smith and Frawley 1983), discourse markers (Morenberg 2002) and logical connectives (Pinkham 1998).

Although Halliday and Hasan's Cohesion in English (2001) is considered a standard text in cohesion studies, their proposed definition of conjunction in cohesion is challenged as narrow by Smith and Frawley $(1983,355)$. For Halliday and Hasan, conjunction is strictly defined as the part of speech which connects ideas between two sentences, as such conjunctions should occur only in the initial position of a sentence $(2001,226-273)$. If a CE functions to link ideas within one sentence, it is considered as structural instead of a sentential cohesion, because cohesion is technically considered as the texture of a text, which is made up of sentences.

In Smith and Frawley's (1983) initial study, some items are not often identified as conjunctions. According to their report, such findings were based on Halliday and Hasan's (2001) definition that a conjunction only links two separate sentences, or is extra-sentential; and, conjunctions must be used in the initial position of a sentence. This definition limits certain language markers from being identified as conjunctions. Smith and Frawley's (1983) findings dramatically changed after they broadened Halliday and Hasan's definition of conjunctions. The researchers discovered that the texts they had studied were actually rich in cohesion through 
the use of a range of CEs. As a result, they emphasised the need for a less limiting definition of CEs.

Apart from Smith and Frawley's recommendation for a broader definition of CEs, the definition of a sentence or a text is also questioned by Baker (2001). In English and other similar languages with highly developed punctuation systems, the definition of what comprises a sentence is problematic (Baker 2001, 193). While it is usual for the English language to break information into parts, separated and signalled by punctuation markings, it is different for other languages, such as Arabic, in which one whole paragraph may consist of only one sentence (193). When a translator translates a text from languages with less punctuations, such as Arabic, into a language with a highly developed punctuation system, such as English, the notion of a sentence becomes problematic (194-196). As mentioned before, even Halliday and Hasan $(2001,232)$ admit that "the sentence is a very indeterminate category", although they also equally argue that the notion of a sentence is essentially valid.

This study adopts Baker's concept of cohesiveness $(2001,192)$. Baker considers an element as cohesive "as long as it signals a conjunctive-type relation between parts of text, whether these parts are sentences, clauses (dependent and independent) or paragraphs". Therefore, CEs such as "if...then", "although" and other similar subordinating conjunctions will be included in this study. In other words, in this study, the term "conjunctive element (CE)" is employed as a reference to any logical connector, conjunction, transitional device, conjunctive adverb, etc.

CEs indicate the relationship between clauses, sentences and paragraphs. CEs include the simple words in English that hold clauses and sentences together in a meaningful way (Pinkham 1998, 377), such as "too", "then", "finally", "yet" and "if". Unlike other cohesive devices, CEs do not instruct the reader to link up missing information by searching for it elsewhere in the text (Baker 2001, 190). Instead, it is the writer's way of informing the readers about how the text should be understood, by comprehending the following sentence or clause within the context of what has been mentioned before (Baker 2001, 190; Bulow-Moller 1989, 142; Morenberg 2002, 134).

Traditionally, conjunctive relations are classified in terms of coordination, subordination, correlation, etc. Such classifications are syntactically motivated. However, to achieve the aims of this study, Halliday and Hasan's conjunctive relation model of five categories, which is semantically motivated, is employed $(2001,238)$. The five main relation categories are summarised as follows (Halliday and Hasan 2001): 
1. Additive: A relation where a statement is followed by another statement that adds to the first - more information, supporting evidence, elaboration, etc.

Example: and, or, also, in addition, furthermore, besides, similarly, likewise, by contrast, for instance

2. Adversative: Established when two statements are in contrast. The second statement opposes and qualifies the first in terms of sequence.

Example: but, yet, however, instead, on the other hand, nevertheless, at any rate, as a matter of fact

3. Causal: Occurs when a statement or clause shows the consequence of another. CEs in such a relation are crucial for differentiating the cause and the effect.

Example: so, consequently, it follows, for, because, under the circumstances, for this reason

4. Temporal: A relation that is related to time and sequence, whether the events or ideas in two statements come first or later.

Example: then, next, after that, on another occasion, in conclusion, an hour later, finally, at last

5. Continuatives: A relation in which several individual items are brought together in cohesion, yet are not identified by the four cohesive devices above.

Example: now, of course, well, anyway, surely, after all

Like English language, Chinese employs CEs to achieve logical relations between statements. However, Chinese naturally employs fewer conjunctions compared to English (Liu 1992; Lian 1993; Peng 2008) and sometimes uses none at all (Zhang 2000; Pinkham 1998; Liu 1998). Many CEs deemed essential in English texts are freely omitted during translation into Chinese because they would seem redundant (Xu 2003, 54; Liu 1998, 385).

According to Loh $(2000,184)$, CEs which are used to link clauses and sentences in Chinese can be divided into eight relation categories: 承接 (successive), 递进 (progressive), 选择 (discretionary), 取舍 (concessive), 转折 (adversative), 假设 (hypothetical), 条件 (conditional) and 因果 (causal). The eight categories, in some ways, echo Halliday and Hasan's (2001) conjunctive relations model mentioned in the previous section. To facilitate the data analysis in this study, the Chinese categorisations will be incorporated into Halliday and Hasan's simpler and more 
inclusive categorisation. For example, 假设 (hypothetical) and 条件 (conditional) CEs technically express causality in most cases, and therefore, they could be included under the causal relation category.

\section{Cohesive shifts}

Cohesion is the overt relationship extending between elements of a discourse, expressed by certain markers, where the elements are dependent on other elements for an effective interpretation (Halliday and Hasan 2001). This notion of cohesion needs to be discussed in this study as it is closely related to the CEs that form part of the cohesive element alongside references, substitutions, ellipsis and lexical cohesion. In translation studies, the term "translation shifts" has been used to describe "small changes that occur between units in a ST-TT pair" (Hatim and Munday 2004, 142). Thus, the notion of "cohesive shifts" is used in this study. A cohesion shift is indicated by a difference (more or less explicit) in the employment of cohesive markers. In this study, it is used loosely to denote changes that occur between units in a source text-translated text (ST-TT) pair, which includes explicitation (the addition of CEs in the TTs), implicitation (the omission of CEs in the TTs), shifts (any kind of shifts, either position shifts or semantic shifts) and incorrect translations.

The study of the translation of conjunctions mostly focuses on the study of explicitation. The Hypothesis of Explicitation proposed by Blum-Kulka (1986) postulates that the addition of CEs are attributed to the process of interpretation of the ST by the translator during the translation process. According to Blum-Kulka $(1986,300)$ :

The process of interpretation performed by the translator on the source text might lead to a TL text which is more redundant than the SL text. This redundancy can be expressed by a rise in the level of cohesive explicitness in the TL text.

Many studies have been conducted based on Blum-Kulka's hypothesis. Øverås (1998), Olohan and Baker (2000), Pápai (2004), Konšalová, (2007), Soh (2010) and Liao (2011) generally reveal that TTs tend to have increased explicitness. BlumKulka states that "explicitation is a universal strategy inherent in the process of language mediation" $(1986,302)$. Explicitation is a common strategy employed by translators to bridge the gaps between cultures, the differences between language systems, or to achieve the effect of readability and ease of comprehension, as mentioned in Saldanha's (2008) study. While explicitation has its benefits, it can also lead to undesirable results in some cases. The gaps between two different cultures or language systems may be bridged by rendering the texts more "clearly" 
to the target culture, but the translators might "obscure its own mode of clarity" (Berman 1985, 290).

\section{Implication of shifts}

Few studies have focused solely on the implications of translation shifts in CEs; no studies have focused on the implications of shifts in CEs in argumentative texts. As mentioned earlier, studies on the effects of shifts in CEs have been predominantly linked to explicitation. For example, Blum-Kulka (1986) compares the translation of a play, and shows that the explicitation of the CE "so" in a dialogue between a wife and a husband can change or shift the role of the wife and the husband. Mason (1994), in his study on expository text-types, found that the change of the CE "but" to "meanwhile" caused a manipulation in the ideology of the content. Pápai (2004), who works on texts related to technical writing, finds that the explicitation of CEs may result in a TT that is clearer.

A study that delves deep into the effects of shifts in CEs is Grant's (1990) study on narrative styles. Grant's study reveals that stylistic differences between English and French result in a frequent suppression of the CE "and" in the translation, which leads to "an attendant loss in the rhythmic pattern in the sentences" (Grant 1990, 132). Another effect of having to use the word "and" less often in the French translation is the reduction of a full clause to a relative clause, resulting in a distortion of the propositional weight and the neutrality of sentences suggested by coordination (133). Additionally, the suppression of "and" in the TT causes the translation to lose a sense of natural speech (139). She concludes that changes to the CEs in the TT affect the neutrality of the narrator's style and lead to an increased narrator's presence while the original author was in fact trying to minimise her own presence.

Assisted by corpus, Looi (2013) uses Halliday and Matthiessen's (2004) conjunctive category to account for the semantic categories of conjunctions used in TTs and non-translated texts. The frequency of the use of conjunctions in the TTs and non-translated texts are generated, and these conjunctions are categorised, and comparisons are made. The study found that there was an increase in formalism, connectedness, concessiveness, conditionality and purposefulness, and a decrease in adversativeness in the TTs when compared to the non-translated texts.

\section{Data and Methodology}

The data collected is from a total of nine articles compiled in Ceritalah 3: A Malaysian Dream Deferred, authored by Karim Raslan, an experienced 
political analyst. He founded the public affairs consulting firm, KRA Group, which has an ASEAN-wide focus. His columns are also published in Indonesia's The Jakarta Globe and Kontan newspapers, as well as Singapore's Today. Karim has also appeared as a commentator on Southeast Asia with the BBC, CNN, CNBC, Al-Jazeera and Bloomberg. Ceritalah 3 chronicles the dreams, hopes and fears of Malaysians from different perspectives, which sometimes arise from Karim's own thoughts, and at other times through a side story he had heard while having breakfast in a coffee shop.

The articles in the book are grouped into two parts: part one "The Age of Certainty?" addresses issues surrounding Malaysia's general election in 2004, and part two "The Age of Upheaval" discusses issues surrounding the general election in 2008. The nine articles that are chosen are articles written after the 2008 election, which record the doubts and hopes of fellow Malaysians after the 2008 general election according to Karim. The period after the 2008 election observed the return of Anwar Ibrahim, who was the Deputy Prime Minister of Malaysia prior to his dismissal, and who later became a prominent opposition leader. It was a time when the opposition parties gained more support, and Malaysians were beginning to demand a better governance. A strengthening opposition, dissatisfied citizens and a complacent Barisan Nasional (BN, the governing political party since the independence of Malaysia in 1957) resulted in a turbulent political culture. The nine articles selected from Karim's book for this study are argumentative in nature, as they are constructed to persuade or to convince the readers that the author's analysis and opinions are logical and reasonable. In such argumentative texts, conjunctions play an important role to guide the interpretation of the two propositions. Thus, the translation of conjunctions, albeit a single word or a short phrase, must be scrutinised to ensure the logical connection of the two propositions is what intended by the author.

The target text《凯唾成珠3: 马来西亚一延滞的梦想》(Pearls from Karim's Saliva 3: Malaysia - A Deferred Dream) was published by Sin Chew Daily in 2010. According to the copyright page of the translated book, it was translated by three translators: 陈莉珍 (Chen Li Zhen), 曾慧金 (Zeng Hui Jin) and 罗邦龙 (Luo Bang Long). Throughout the last decade, regularly translated column articles by Karim have become a bridge for the Chinese readers to understand Malaysia from the eye of a critical current affairs analyst. The arrangement of the translated book follows the structure of the original book.

Regarding the methods of study, the nine sets of source texts (STs) and TTs are first placed side-by-side to identify CEs in both texts after which they before being categorised based on Halliday and Hasan's (2001) conjunctive framework. 
Instances of explicitation, implicitation, shift and incorrect translation are then identified. Explicitation occurs when there is no CE in the STs, but the translators have added a conjunctive element; implicitation occurs when there is a $\mathrm{CE}$ in the STs, but the translators have omitted the CE; a shift occurs when a CE has undergone a shift in its position or when a $\mathrm{CE}$ has been shifted to or replace by another $\mathrm{CE}$ with a different semantic meaning, while an incorrect translation occurs when the translation, addition or omission of CEs in the TT causes the TT to have a different meaning from the ST. The impact or implications of these arbitrary alterations in the translation will be discussed in detail, with examples to illustrate each type of implication.

Throughout the study, we do not assume the perspective of the author or the translator. We analyse the texts as a reader who understands the languages of both the original and the translated work. One limitation of this study, then, is this position we take as the ideal readers of both the source language (SL) and target language (TL) texts, assuming to understand fully how both languages are used by the native speakers of both English and Chinese. However, this subjectivity is overcome through the objectivity achieved via the theoretical frameworks that underpin this study.

In the discussion, literal back translations (BT) are provided for the examples used. The BTs allow non-Chinese readers to understand the TT translations. Native speakers of English might find the BTs grammatically incorrect or unnatural. It is inevitable and is intended to be so to aid in understanding how the CEs work in the Chinese translations. The BTs are produced by closely following the TTs, with no reference to the STs.

\section{Analysis}

A detailed analysis of the selected data has revealed that there are a few significant implications in the way CEs are translated in the TTs. The implications are listed below with a few examples for illustration purposes.

\section{Alterations in the intensity of the message}

The analysis of the date revealed that some shifts in CEs alter the intensity of the author's messages, usually making them more intense. Example 1 is taken from the additive relation category. It shows a common phenomenon of explicitation, where the translator reads too much into the ST, which results in a more explicit and emotional translation. In the example below, Karim discusses the way the opposition had gained an unexpected foothold in the 2008 general election in Malaysia. 
Example 1

ST: With state governments tumbling and a drastically reduced parliamentary majority, the people of Malaysia have made themselves heard loud and clear.

TT: 马来西亚人民终于勇敢表达自己的心声，令国阵政府狠狠地摔了 一跤，不止痛失多个国会议席，也失去了几个州属的执政权。

BT: The people of Malaysian finally express themselves bravely, causing the BN to badly fall, not only painfully lost many parliamentary seats, (they) also lost the ruling power in several states.

Apart from using strong and emotional words such as 痛失 (painfully lost) and 狠狠地摔了一跤 (to badly fall), the extra additive CE 不止 .... 也 (not only ... also) increases the intensity of the whole sentence in describing the current state of Malaysia. If we read the ST carefully, we realise that the author was merely describing three factual events (i.e., the state governments are tumbling, the parliamentary majority is drastically reduced, and the people of Malaysia have made themselves heard loud and clear) without assuming the political party's emotions. The addition of 不止 ... 也 is a result of over-interpretation, which occurs during the process of translation, stating that the ruling party BN "badly fall, not only painfully lost many parliamentary seats, (they) also lost the ruling power in several states", while the source merely states "with state governments tumbling and a drastically reduced parliamentary majority".

Example 2 below is an instance where the causal CE in the TTs has caused increased intensity in the message:

\section{Example 2}

ST: Once again, I have to disagree with them on this point: UMNO's poor showing on March 8 was due to its refusal to acknowledge and address core issues of justice, fairness and equality ...,

TT: 我完全不赞同他们的说法, 巫统之所以在 308 大选表现差强人意, 全因他们不愿意承认和解决这些和正义、公正及平等有关的核心问 题。

BT: I completely disagree with them, the reason UMNO performs poorly in the election on March 8 was entirely because they were unwilling to acknowledge and solve core issues related to justice, fairness and equality. 
In this example, Karim informs the readership that the United Malays National Organisation (UMNO), Malaysia's largest political party, did not perform well during the election due to its refusal to address the issues of justice, fairness and equality. It is very difficult to translate the entire prepositional structure in the ST which contains "due to" into a prepositional phrase in Chinese, and thus, it is acceptable to translate the preposition into structures with conjunctions such as 因 此 (because of that) or 因为 (because). However, the translator has translated the sentence using 全因 (entirely because), which is much more intense because of the modifier 全 (completely/entirely). As such, the translation has entirely shifted the blame of UMNO's failure to its refusal to acknowledge and address the core issues; it is, however, clear that the ST author did not intend to rule out every other reason for UMNO's failure. Altering the intensity of the messages may seem innocuous, but too much intensification may mislead the readers to believe that the author, Karim Raslan, is an emotional and trenchant critic of UMNO, when, in fact, he is rational and objective in putting forward his views.

\section{Shifts of focus}

By moving an adverb to the initial position of a sentence, the conjunctive function of the adverb is emphasised, and the logical relation is brought into focus in the TTs. Such a shift of focus caused by the movements of adverbs can be seen in Example 3 below:

\section{Example 3}

ST: There is also a sense of political loyalty and discipline.

TT: 而且, 他们对政治忠诚、有纪律。

BT: Moreover, they are loyal and disciplined with regard to politics.

In Example 3, the context is that the Democratic Action Party (DAP) and the Malaysian Islamic Party (Parti Islam Se-Malaysia, PAS), the opposition parties, comprise a group of leaders who share certain core beliefs, experiences, discipline and a certain sense of political loyalty. The author could have initiated the sentence in the ST by moving the adverb "also" to the front, but he did not. He did not intend for it to be a sentence connector, but an adverb of addition in the sentence. In the TT, the translator has chosen to translate "also" as an additive CE 而且 (moreover) when he could have translated it as 也 (also) which is a perfectly corresponding adverb to “also" in English, i.e., 他们也对政治忠诚、有纪律 (they are also 
loyal and disciplined with regard to politics). The shift has changed the nuance of the source text, although it does not directly alter the entire meaning of the text. According to the theme-rheme metafunction by Halliday and Matthiessen (2004), the theme, or the most important point of the sentence, is usually mentioned first, increasing the weight of the words. The source text sentence in Example 3 appears to be an added remark. In the target text, however, the continuity of the simple sentence is disrupted by this arbitrary shift of the adverb to a conjunction, or a shift of the adverb to the front of the sentence. Since 而且 (moreover) is an additive CE, but pre-posing it has elevated the importance of the message after the pre-posed adverb or conjunction, which changes it from functioning as a casual, bonus-like addition.

Apart from changes in the position, focus shifts also occur when CEs are added or translated differently. Example 4 shows the way shifts of CEs affect the focus of the text even though the translation is not necessarily wrong:

\section{Example 4}

ST: Their decades-old marginalisation and more recent attacks such as temple demolitions have united them against the establishment.

TT: 由于长期被边缘化, 加上近期兴都庙被拆除事件, 已引起印裔社 群强烈不满, 继而联合起来反抗政府。

BT: Due to (them) being marginalised perennially plus the recent event of Hindu temple demolition have already caused the Indian community's strong dissatisfaction, thereby (they) unite against the government.

In Example 4, the author presents the reasons Indians unite against the government, and so, the focus is apparently not on the timeline, but the cause and effect of the events. The ST merely lists the possible factors which have led the Indians to rise against the government. However, in Chinese, 继而 (then) is a temporal CE, which indicates a progression of events. It is not to be confused with 因而 (therefore), which indicates a causal relation. The TT shows a temporal progression of events, especially marked by the CE 继而 (then): first the Indians experienced perennial marginalisation $\rightarrow$ then there was a recent attack (temple demolition) $\rightarrow$ then the Indians have resentments $\rightarrow$ then Indians unite against the government. It is thus shown that using a different $\mathrm{CE}$ could alter the focus of a text; in this case, it has altered the focus from the cause and effect to the temporal unfolding of events. 
Example 5 below demonstrates another shift of focus due to shifts in CEs:

Example 5

ST: The alliance is fragile, having a slim two-seat majority in the State Assembly, not to mention a supremely confident and vigilant palace. All eyes, therefore will be on new PAS Menteri Besar, engineer Mohamad Nizar Jamaluddin and the two DAP strongmen/lawyers in the exco, Ngeh Koo Ham (reputedly the first ever Datuk in the DAP) and Nga Kor Ming, also the head of the party's Youth wing (Dapsy).

TT: 民联是脆弱的, 它在州议会仅以区区两个多数议席执政, 更甭提 中间还有一个信心和戒备心慢慢的皇室。如今焦点全落在来自回教党 的新任州务大臣尼查, 以及行政议会的两位行动党强人倪可汉（据说 是首位获封拿督的行动党人) 和社青团团长倪可敏的身上。

BT: The alliance is fragile, it has a slim two-seat majority in the State Assembly, not to mention a supremely confident and vigilant palace. Now, all eyes are on the new Menteri Besar Nizar and the two DAP strongmen in the exco, Ngeh Koo Ham (reputedly the first Datuk in the DAP) and Nga Kor Ming, the head of the party's youth wing.

In the context of the text, Karim comments that many people had looked to the new Pakatan Rakyat party (an informal Malaysian coalition political party, consisting of Parti Keadilan Rakyat or PKR, DAP and PAS, which is the major rival of BN) in the state of Perak to revive the economy of the state. That was the reason why people were paying attention to the PAS and DAP political leaders. In Example 5, the causal CE "therefore" in the ST is substituted by a temporal CE 如今 (today/ now). This is considered an optional shift because "therefore" has a perfectly corresponding translation: 因此 (therefore). It is not an erroneous translation because both CEs point to the latest situation where it depends on the three Pakatan Rakyat leaders to lead the future of Perak after the failure of the past governance. However, the main message of the ST is that the past failure has now put a heavier burden on Pakatan Rakyat, and it is the reason why "all eyes will be on the new Pakatan Rakyat". Inserting the temporal CE 如今 instead of "therefore" does not only shift the focus of the text, it also dilutes the meaning of the causal relation.

\section{Alterations in tone and manner}

In this study, shifts of CEs are also found to alter the tone and manner of the text. Such alterations usually occur when CEs like 若 ... 则 (if ... then) are added in the TT: 
Example 6

ST: Finally, you do not learn about these issues by refusing to discuss them.

TT: 若拒绝一切讨论, 则永远无法认识这些存在的问题,

BT: If you reject every discussion, then you can never understand these existing issues.

\section{Example 7}

ST: A failure to do so would be fatal both to him and UMNO.

TT: 若他失败的话, 则对巫统和他本身而言都是致命的一击。

BT: If he fails, then it would be fatal to him and UMNO.

Examples 6 and 7 demonstrate two instances where implicit causal relations are made explicit by adding causal CEs 若 ... 则 (if ... then). 若 ... 则 (if ... then) in Examples 6 and 7 mark conditional relations which fall under the causal relation category. Example 6 is about the incident where the Bar Council convened a forum proceeding named "On Conversion to Islam" on August 9 to discuss the legal conflict that might arise due to the conversion to Islam. The forum was halted because 300 protesters gathered outside the council's headquarters, demanding the professional association to stop the forum. Commenting on the incident, Karim states that a person will not understand an issue if he does not discuss it. Example 7 is about Najib Abdul Razak, the then would-be Prime Minister, who is expected to be confident to face scrutiny to "head off the criticism and prepare his party for a more people-friendly future". If not, it would be detrimental to him and to his party. Like the translators, the author could have employed conditional CEs in these two sentences, but he chose to construct his sentences in a more direct way. In these examples, the ST author, consciously or unconsciously, has empowered his assertions or made them more persuasive. In most cases, the extra causal CEs 若 ... 则 (if ... then) in the TT can be removed without affecting the meaning. 拒绝一切讨论, 永远无法认识这些存在的问题 and 无法办到这 点, 对巫统和他本身而言都是致命的一击. This phrasing will keep the causal relations implicit (as Chinese language employs less conjunctions). Apart from explicitly expressing the causal relation of the texts, CEs such as 若 ... 则 (if ... then) also highlight the fact that certain events in the statements may or may not happen, the statements are only suggestions or opinions. As a result, the use of 若 ... 则 (if ... then) causes the TTs to have a refrained or reserved tone and manner compared to the STs, which are more assertive. 


\section{Production of repetitious and intrusive translations}

The English language employs more CEs to establish logical relations in a text compared to Chinese. If every English CE in a text was rendered faithfully into Chinese, the TT would probably contain many superfluous CEs. The following two examples are taken from the causal relation category, where no CEs were employed in the ST but were added in the TT:

\section{Example 8}

ST: By talking down to them and treating them with gross disrespect, the BN is simply reaping the bitter harvest of excluding the youth from the political process through draconian laws like the Universities and University Colleges Act 1971.

TT: 国阵总是用居高临下的态度对待这些年轻人，甚至通过专横的 1971年大专法令将他们排除在民主政治外, 因此获得这样的选绩不外 乎是自食其果。

BT: The BN has always treated these youths with a condescending attitude, (it) even excluded them from democracy through the draconian Universities and University Colleges Act 1971, therefore obtaining such result is none other than reaping what it has sown.

\section{Example 9}

ST: Their disgruntlement over the NEP, the creeping pace of Islamisation and their utter alienation from the national life have proven to be the downfall of Gerakan and the MCA.

TT: 新经济政策、回教化和被孤立化的现象, 让他们极度不满, 因而 促成了民政和马华的垮台。

BT: The NEP, Islamisation and the phenomena of alienation have left them extremely dissatisfied, therefore leading to Gerakan and the MCA's downfall.

In Example 8, Karim comments that the ruling party BN, reaped the bitter harvest of excluding the youth in the political process. The causal relation of the TT is clearly expressed through the underlined clause 获得这样的选绩不外乎是 自食其果 (obtaining such result is none other than reaping what it has sown), especially in the idiom 自食其果 (reap as one has sown). The extra causal CE 因此 (therefore) is unnecessary. For Example 9, the context is that the Chinese 
people in Malaysia are unhappy with the NEP (the New Economic Policy which mainly favours the Malays), the domination of Islam and being excluded from the public workforce. The combination of these issues has caused the downfall of progovernmental political parties such as Gerakan and MCA, which are dominated by the Chinese. In Example 9, the causal relation in the ST is expressed by the phrase "has proven to be", indicating that whatever was mentioned before the phrase is the cause of the outcome mentioned afterwards. The phrase can be replaced with other verb phrases such as "led to, brought about". The translator translated "has proven to be" as 促成 (lead to, bring about, causes), yet he also made the causal relation explicit by adding an extra causal CE 因而 (therefore), which is deemed unnecessary because 促成 expresses the causal relation sufficiently. This phrasing shows that explicitation leads to repetitious and intrusive translations due to the use of unnecessary CEs in the TTs.

Example 10 is another example that demonstrates how simple sentences are made overly complex in the TT due to the overuse of CEs:

\section{Example 10}

ST: “...They are dealing with a state that's over 95\% Malay. Perak is a very mixed environment. We can't approach governance in the same way." Despite his reassurances, the fragility of the links between PAS and DAP is clear for all to see.

TT: “...他们管治的那个州, 超过 $95 \%$ 是马来人; 反观霹需则是一个多 元种族混合的州属, 近以我们无法用相同的管理方式。[”] 尽管他一再 保证, 但大家都清楚知道回教党和行动党之间的联系其实并不大。

BT: The state which they govern have more than 95\% of Malay; in contrast Perak is a multi-racial state, therefore we cannot govern it using the same method. Even though he reassures repeatedly, but everyone knows clearly that the link between PAS and DAP are actually weak.

The direct speech in Example 10 was spoken by Mohamad Nizar Jamaluddin, a member of PAS, and the chief minister of the Malaysian state of Perak at that time. Mohamad Nizar Jamaluddin was asked to compare himself to two other leaders in the same political party who were dealing with issues in Kelantan, where the Malays are dominant. In the ST, not a single CE is used to indicate the logical relations between sentences. Even though overtly marking the relations is possible, the author chose not to do so. On the other hand, the logical relations of the TT were explicitated through the use of three CEs: 反观 (in contrast), 所以 (therefore) and 尽管 ... 但 (even though ... but). Being able to establish logical 
relations also means that CEs have the ability to instruct the readers on the way that texts should be comprehended. Karim is simply quoting Nizar's statements using direct and simple sentences; the logical relations between the statements are easy to understand. The author allows his readers the freedom to link the connection between sentences by using less CEs. Nevertheless, such freedom is restricted in the translation, as the translators chose not to follow the structure of the ST, although they could have done so without changing the meaning of the text. Too many CEs can be intrusive to the mind, as they tend to disrupt the readers, telling them how they should read the text.

\section{Changes in the interpretation of the text}

The translation of CEs may also change the interpretation of the ST. Example 11 illustrates an incorrect translation of the preposition "without" into 而非 (but not), which changes the interpretation of the text:

\section{Example 11}

ST: As the 'Malayan' half of the PAP after the 1965 Separation, the DAP inherited the socialist rhetoric without Lee Kuan Yew's mean-spirited realpolitik.

TT: 作为1965年马新分家后新加坡人民行动党 (PAP) 在马来亚的分 部, 它承继了社会主义的精髓, 而非李光耀狭窄的使用政治。

BT: As the branch of the PAP in Malaya after the 1965 Separation, it inherited the essence of socialism, but not Lee Kuan Yew's myopic realpolitik.

In Example 11, DAP, dominated by the Chinese, is compared to the People Action Party (PAP), a centre-right political party in Singapore. Lee Kuan Yew, the leader of the PAP became the President of Singapore after the separation of Singapore from, what was then, the Federation of Malaya. In Example 11, 而 (but) is a CE while 非 (not) is a negating verb. The meaning is subtly changed after translation. In the ST, "without" signifies that the DAP has inherited the rhetoric of socialism, but without Lee Kuan Yew's realpolitik. The ST suggests that realpolitik is a related to socialism, or maybe a form of socialism. Conversely, 非 (not) in the TT suggests that realpolitik is not socialism, and they are two distinctively different ideas. Therefore, the target text has not done the original text justice. To restore the original meaning, 而非 (but not) can be replaced by the word “少了” (without/not having), which carries the same meaning as "without" in the ST. 
Example 12 demonstrates a wrong translation of the additive $\mathrm{CE}$ "and" into a causal CE 由此可见 (hence one can see that), which distorts the meaning of the ST:

\section{Example 12}

ST: While I have to agree that the Pakatan's increasing proximity to the apex of power - namely Putrajaya - has made it more united, I would also argue that there are some powerful ideological forces at work in the three component parties, and that these political philosophies do mesh.

TT: 我必须承认, 民联由于攀上权力的巅峰（亦即布城）而变得更加 团结, 不过也有可能是因为一股庞大的意识形态潜移默化在这三个党 内起了作用, 由此可见他们的政治理念是一致的。

BT: I must admit, the Pakatan because of climbing to the apex of power (which is Putrajaya) therefore became more united, but it also may be because a huge ideology is subtly taking effect in these three parties, hence one can see that their political ideal is unanimous.

In the context of the above text, Karim comments that the three component parties, namely, PKR, DAP and PAS, that form the Pakatan Rakyat are moving towards Putrajaya, the federal administrative centre of Malaysia. In the ST, the author is suggesting that there are different ideological forces at work and that the different ideologies do not conflict with each other - this is the main thesis of the whole article which the author later supports with evidence. The two propositions in the ST are connected with the CE "and". However, the translator mistranslated the italicised ST phrase “some powerful ideological forces at work" as 一股庞 大的意识形态 (a huge ideology), and the CE as 由此可见 (hence one can see that), and ended with "their political ideal is unanimous". The translator clearly misunderstood the ST and mistranslated the CE with a causal CE.

Example 13 also reveals an incorrect translation where the addition of a causal CE 因为 (because) in the TT totally reverses the original meaning of the text, causing the translation to have a different meaning compared to the ST:

\section{Example 13}

ST: As I will explain later, in the case of Najib, his continuing refusal to endorse and promote the civil liberties reform agenda is actually undermining his own career. 
TT: 正如我待会解释的那样, 纳吉一直不愿促成民主权益的改革议 程，因为这在很大程度上将削弱它本身的的政治事业。

BT: Just as I will explain later, Najib has been reluctant to promote the civil liberties reform agenda, because this will undermine his own political career to a great extent.

The author meant to say that Najib's (the sixth Prime Minister of Malaysia) reluctance to endorse the reform agenda will undermine Najib's own career. Due to the addition of 因为 (because), the TT conveys the following: that Najib is reluctant to endorse the reform agenda because the endorsement will greatly undermine his political career. The translation would have been correct if the translator had not added the causal CE. If any CE is to be used here, 其实 (actually) would have been most appropriate.

Example 14 presents another mistranslation involving an adversative CE, thus changing the interpretation of the ST:

\section{Example 14}

ST: As a consequence, I would argue that inherent misunderstandings and tensions across the racial and religious divide have not miraculously evaporated in the face of an Anwar Ibrahim-inspired political love-in.

TT: 结果, 我会主张说, 不同种族和宗教之间固有的意见分歧和紧张 情绪纵使受到安华政治集会的影响, 但却也没有出乎意料地消失。

BT: Consequently, I would advocate that, the inherent disagreements and tensions across the races and religions even though influenced by Anwar's political gatherings, but they did not unexpectedly disappear.

As indicated by the causal CE "as a consequence", the statement in Example 14 is Karim's conclusive argument after presenting several substantiations before this statement. It is the author's claim that Malaysia is by no means beyond racial tensions and that the people's unity was precipitated by a nationwide resentment towards the then prime minister, Abdullah Badawi. The author is actually trying to dissociate the people's unity from Anwar's political efforts. Therefore, the statement in Example 14 is a conclusion that needs to be handled carefully. Unfortunately, the addition of the correlative adversative CE 纵使 ... 但 (even though ... but) has distorted the meaning of the message. Due to the added CE, the TT in Example 14 basically means that racial tensions, despite being affected by Anwar's political gatherings, still exist as expected by the author or Malaysians. Such a translation 
implies that Anwar's political movements have played a role in eradicating racial tensions. This implication is actually contrary to the author's effort to dissociate Anwar's influence with the seemingly dissipating racial dissents.

\section{Altering the conversational-like element in the source text}

It was also evident that shifts in the use of continuatives could change the conversational-like element in the ST into a more formal-sounding discourse. According to Halliday and Matthiessen $(2004,81)$ "a continuative is one of a small set of words which signals a move in the discourse: a response, in dialogue, or a new move to the next point if the same speaker is continuing". They are also markers for conversation, such as the CE "well".

\section{Example 15}

ST: Well, a sustained period in opposition will give the party a chance to reinvent itself.

TT: 由执政党移位成反对党, 无疑给了它一个改过自新的机会。

BT: A change from the ruling party into the opposition, undoubtedly gives it a chance to renew itself.

\section{Example 16}

ST: Well, I have news for them: we didn't 'betray' them - they betrayed us (fully $49 \%$ of the voters opted for the opposition).

TT: 我想告诉他们的是: 我们并没有背叛他们, 是他们背叛了我们 (49\%的选民把票投给了反对党)。

BT: I want to tell them this: we did not betray them, it's them who betrayed us ( $49 \%$ of the voters voted for the opposition).

In written Chinese, there is no corresponding item which carries the feature of continuative CEs such as "well", as shown in Examples 15 and 16. According to the Cambridge Online Dictionary (2014), "well" is used to introduce something you are going to say, often to show surprise, doubt, slight disagreement, or anger, or to continue a story. Here, the continuative is used to introduce the same speaker's explanatory comment. The nearest equivalence may be 唔 (read as "mmm"), which is an onomatopoeic sound which imitates the sound one makes during a 
short pause before saying the next thing. The introduction of "mmm" in translation may help to achieve the effect of casual conversation in Chinese too, but it is not the norm in Chinese to use it in a formal or semi-formal context.

This study has shown that the author, Karim Raslan, writes with a very colloquial flair, utilising the CE such as "well" to give his articles a conversational flow. These continuative CEs can be removed in the ST itself without much effect, except for maybe the loss of the casual conversational tone that the author tries to create. Many of these CEs are not literally translated into Chinese since Chinese texts do not rely on these devices to imitate conversational speech. The lack of these CEs in the TTs is the main reason the TTs have fewer continuative CEs compared to the STs. One way to mimic the conversational style of the author's writings is to use more interjections and exclamations, such as 啊, 恩, 唔, 咦 (ah, um, uh, oh), when appropriate. Utterance particles in the final position of a sentence (句末语 气助词) such as 啦, 呢, 吧, 啊, 哦 (la, neh, ba, ah, oh) can also be used more frequently whenever the author intends to write in a casual tone. Of course, this may be rejected depending on the publisher's conventions or the target language conventions on constructing argumentative text, which ultimately determines whether such tones of informality or colloquialism are acceptable.

\section{Conclusion}

This study has presented six implications of CE shifts in the translation of argumentative texts. The first implication observed is the altering of the message's intensity where the addition of CEs, or the addition of an intensified modifier to the CEs, as given in the first two examples, may alter the intensity of the message. The two examples have shown how, in the TT, Karim Raslan can be portrayed as being too emotional in opposing the ruling party.

Additionally, this study has also shown how shifts in CEs can divert the focus of the texts. Focus shifts occur when the position of a conjunctive adverb is moved from the middle of a sentence to the initial position of a sentence, and vice versa. Pre-posing conjunctive adverbs to the front highlights their alternate function as CEs. The movement also brings the logical relation indicated by the CEs into focus. Apart from movements of positions, shifting the CEs from one semantic meaning to another can also lead to focus shifts. Focus shifting, to an extent, can dilute the meaning of a text.

The examples presented in this study have clearly shown that shifts in CEs can alter the tone and manner of the texts. When assertive statements with no causal $\mathrm{CE}$ to express conditional relation are translated into statements with causal CEs, 
the assertive tone of the texts is weakened. The translations sound more cautious and reserved, as the causal CEs explicitly signal the reader to take the statements as suggestions or opinions.

The fourth implication is that the shifts of CEs may cause repetitious and intrusive translations. Very often, translators chose to make a logical relation explicit without realising that the relations are already marked through other parts of speech such as verbs and idioms as shown in Examples 8 and 9. Texts with superfluous CEs can be wearisome to the reader. Similarly, too many explicitations due to the use of CEs can be intrusive, making texts even more complex, and thereby preventing a straight-forward and clear interpretation of the text.

The fifth implication is due to mistranslation of CEs, which will lead to a misinterpretation of the text. Since CEs function to establish logical relations, a wrong translation will lead to a change in logical relations. These changes in logical relations can completely distort the original message and misrepresent the author in the translation, as is evident in Examples 11-14.

The last implication involves shifting the tone from casual to formal by dropping the conversational elements in the ST. This shift may be due to the convention of the target language, which does not allow certain conversational elements to be present.

Shifts do occur in the translation of CEs. This study has revealed that CEs in argumentative texts, such as column articles, should be translated as faithfully as possible. It is better to keep the logical relations implicit rather than misinterpret them. Some of the added or incorrectly translated CEs in this study give rise to translations with completely opposite meanings to that in the ST. Thus, understanding the ways CEs work can effectively minimise the risk of inaccurately shifting the meaning presented to the target reader.

\section{References}

Baker, M. 2001. In other words: A coursebook on translation. London and New York: Routledge.

Berman, A. 1985. La traduction comme épreuve de l'étranger (Translation and the trials of the foreign). In The translation studies reader, ed. L. Venuti, 284-297. London: Routledge.

Blum-Kulka, S. 1986. Shifts of cohesion and coherence in translation. In The translation studies reader, ed. L. Venuti, 298-313. London: Routledge.

Bulow-Moller, A.M. 1989. The textlinguistic omnibus: A survey of methods for analysis. Kobenhavn: Nyt Nordisk Forlag Arnold Busck. 
Chen, L.Z., Zeng, H.J. and Luo, B.L. 2010. 凯唾成珠3：马来西亚一延滞的梦想 (Pearls from Karim's Saliva 3: Malaysia - A deferred dream). Petaling Jaya: Sin Chew Daily News.

Grant, L.E. 1990. Translating Mavis Gallant into French: The effect of translation shifts on narrative styles. http://summit.sfu.ca/system/files/iritems1/4610/b14455079.pdf (accessed 30 May 2016).

Halliday, M.A.K. and Hasan, R. 2001. Cohesion in English. Beijing: Foreign Language Teaching and Research Press.

Halliday, M.A.K. and Matthiessen, C.M.I.M. 2004. An introduction to functional grammar. London: Hodder Arnold.

Hatim, B. and Mason, I. 1990. Discourse and the translator. London and New York: Longman.

Hatim, B. and Munday, J. 2004. Translation: An advanced resource book. London: Routledge.

Konšalová, P. 2007. Explicitation as a universal in syntactic de/condensation. Across Languages and Cultures 8(1): 17-32. https://doi.org/10.1556/Acr.8.2007.1.2

Lian, S.N. (连淑能). 1993. Yinhan duibi yanjiu 英汉对比研究 (English-Chinese comparative study). Beijing: Gaodeng Jiaoyu Chubanshe.

Liao, M.S. 2011. Interaction in the genre of popular science. The Translator 17(2): 349368. https://doi.org/10.1080/13556509.2011.10799493

Liu, M.Q. (刘宓庆). 1992. Hanyu duibi yu fanyi 汉语对比与翻译 (Chinese language comparison and translation). NanChang City: Jiangxi Education Publishing House. (刘宓庆). 1998. Wenti yu fanyi 文体与翻译 (Style and translation). Beijing: China Translation Corporation.

Loh, H.Y. (罗华炎). 2000. 现代汉语语法 (Modern Chinese grammar) (6th ed.). Kajang: Penerbitan Seni Hijau.

Looi, W.L. 2013. Explicitation, implicitation and shift of conjunctions in English-Chinese translation of institutional texts: A corpus-assisted study. PhD dissertation, SOAS University of London.

Mason, I. 1994. Discourse, ideology and translation. In Language, discourse and translation in the West and Middle East, eds. R. de Beaugrande, A. Sunnaq and M.H. Heliel, 23-34. Amsterdam and Philadelphia: John Benjamins Publishing Co. https://doi. org/10.1075/btl.7.06mas

Morenberg, M. 2002. Doing grammar. Oxford: Oxford University Press.

Olohan, M. and Baker, M. 2000. Reporting that in translated English: Evidence for subconscious processes of explicitation? Across Languages and Cultures 1(2): 141158. https://doi.org/10.1556/Acr.1.2000.2.1

Øverås, L. 1998. In search of the third code. An investigation of norms in literary translation. Meta 43(4): 571-590. https://doi.org/10.7202/003775ar

Pápai, V. 2004. Explicitation: A universal of translated text? In Translational universals: Do they exist?, eds. A. Mauranen and P. Kujamäki, 143-164. Amsterdam: John Benjamins Publishing Co. https://doi.org/10.1075/btl.48.12pap

Peng, X.L. (彭晓琳). 2008. Comparison of English-Chinese conjunction in process and English-Chinese translation methods (散文中英汉连词对比及汉译英处理方法). Journal of Chongqing Jiaotong University (Social Sciences Ed.) 8(5): 127-130. 
Pinkham, J. 1998. The translator's guide to Chinglish. Beijing: Foreign Language Teaching and Research Press.

Raslan, K. 2009. Ceritalah 3: A Malaysian dream deferred. London: Marshall Cavendish. Saldanha, G. 2008. Explicitation revisited: Bringing the reader into the picture. Trans-kom 1(1): 20-35.

Smith, R.N. and Frawley, W.J. 1983. Conjunctive cohesion in four English genres. Text 3(4): 347-374. https://doi.org/10.1515/text.1.1983.3.4.347

Soh, B.K. 2010. Cohesion and coherence shifts in Chinese argumentative texts translated from English. PhD dissertation, University of Malaya, Malaysia.

Werth, P. 1984. Focus, coherence and emphasis. London: Croom Helm.

$\mathrm{Xu}$, J.P. 2003. 英汉互译: 实践与技巧 (English-Chinese translation: Practice and techniques). Beijing: Qinghua Daxue Chubanshe.

Zhang, M.S. 2000. Cohesive features in the expository writing of undergraduates in two Chinese universities. RELC Journal 31(1): 61-95. https://doi. org/10.1177/003368820003100104 